Thoolen, B.J., Ridder, D. de, Bensing, J., Gorter, K., Rutten, G. Beyond good intentions: the role of proactive coping in achieving sustained behavioural change in the context of diabetes management. Psychology \& Health: 2009, 24(3), 237-254

\begin{tabular}{|l|l|}
\hline Postprint Version & 1.0 \\
\hline Journal website & $\underline{\text { http://www.informaworld.com/smpp/content } \sim \mathrm{db}=\text { all } \sim \text { content=a791048222 }}$ \\
\hline Pubmed link & $\underline{\text { http://www.ncbi.nlm.nih.gov/pubmed/20204991 }}$ \\
\hline DOI & $10.1080 / 08870440701864504$ \\
\hline
\end{tabular}

This is a NIVEL certified Post Print, more info at http://www.nivel.eu

\title{
Beyond good intentions: The role of proactive coping in achieving sustained behavioural change in the context of diabetes management
}

\author{
Bart Johan ThoOlena; Denise De RidDera; JoZien BensingB; KeEs GORTERC; GuY RutTenC \\ ${ }^{a}$ Faculty of Social Sciences, Department of Clinical and Health Psychology, Utrecht University, Utrecht, \\ 3508 TC, The Netherlands \\ ${ }^{\mathrm{b}}$ NIVEL: Netherlands Institute for Health Services Research, Utrecht, $3500 \mathrm{BN}$, US \\ c Julius Center for Health Sciences and Primary Care, 3508 GA Utrecht, US
}

\begin{abstract}
This study examines the effectiveness of a brief self-management intervention to support patients recently diagnosed with type-2 diabetes to achieve sustained improvements in their self-care behaviours. Based on proactive coping, the intervention emphasizes the crucial role of anticipation and planning in maintaining self-care behaviours. In a randomised controlled trial among recent screen-detected patients, participants who received the intervention were compared with usual-care controls, examining changes in proximal outcomes (intentions, selfefficacy and proactive coping), self-care behaviour (diet, physical activity and medication) and weight over time (0, 3 and 12 months). Subsequently, the contribution of proactive coping in predicting maintenance of behavioural change was analysed using stepwise hierarchical regression analyses, controlling for baseline self-care behaviour, patient characteristics, and intentions and self-efficacy as measured after the course. The intervention was effective in improving proximal outcomes and behaviour with regard to diet and physical activity, resulting in significant weight loss at 12 months. Furthermore, proactive coping was a better predictor of long-term self-management than either intentions or self-efficacy. Proactive coping thus offers new insights into behavioural maintenance theory and can be used to develop effective selfmanagement interventions.
\end{abstract}

\section{INTRODUCTION}

Diabetes management confronts patients with numerous challenging health behaviours and many patients find it difficult to initiate and maintain these over any length of time (Glasgow \& Eakin, 1998). While a certain motivation and perseverance may be needed to change one's behaviours, successful maintenance ultimately depends on one's ability to anticipate and deal with a wide range of potential stressors, before they can threaten one's diabetes management and long-term health. This is the central tenet of proactive coping, a self-regulatory model which describes the steps people take in pursuit of their long-term goals (Aspinwall \& Taylor, 1997). While this concept has the potential to explain how people move beyond their good intentions and realise sustained behavioural change, it has received little attention in the context of chronic disease management. In this study, we apply proactive coping to a self-management intervention for patients recently diagnosed with type-2 diabetes. 
Thoolen, B.J., Ridder, D. de, Bensing, J., Gorter, K., Rutten, G. Beyond good intentions: the role of proactive coping in achieving sustained behavioural change in the context of diabetes management. Psychology \& Health: 2009, 24(3), 237-254

The successful treatment of type-2 diabetes ultimately relies on the patient's ability to manage his or her disease, which is considered essential to avoid the long-term micro- and macrovascular complications associated with diabetes. Self-management generally includes self-care behaviours such as dieting, regular physical exercise, numerous medications and a continual self-monitoring on a daily basis, and for the rest of one's life. Incorporating these behaviours into one's lifestyle challenges patients to address conflicting goals, habits and barriers, a difficult task which can have considerable impact on one's family, work and social life. Self-management may be particularly daunting for newly diagnosed patients, who are often asymptomatic, inexperienced and inclined to downplay their risk and treatment (Adriaanse, Snoek, Dekker, van der Ploeg, \& Heine, 2002; Thoolen, De Ridder, Bensing, Gorter, \& Rutten, 2006). But even when they are motivated to change, many patients find it difficult to translate their good intentions into actual behaviour and they also become easily discouraged when their endeavours fail (Glasgow \& Eakin, 1998). This state of affairs suggests that patients need additional support in initiating self-care behaviours and maintaining them over any length of time.

Numerous interventions have been developed to support diabetes patients to improve their selfmanagement. These interventions have become increasingly complex, moving beyond mere knowledge transferal to stress the importance of empowerment, motivation and self-efficacy in helping patients change their behaviours (e.g. Gonder-Frederick \& Cox, 2002; Whittemore, 2000). However, improvements in selfmanagement are usually short-lived, gradually disappearing once intensive contact with professionals is removed (Norris, Engelgau, \& Venkat Narayan, 2001; Steed, Cooke, \& Newman, 2003; Warsi, Wang, \& LaValley, 2004). Most diabetes interventions thus look to be successful at motivating patients to initiate behavioural change, but they do not appear to address the real problem; that is, maintaining new behaviours over time (Rothman, 2000).

More in general, it has been argued that behavioural maintenance has been neglected in behaviour change research (De Wit, 2006; Rothman, 2004). Most theories focus on the initiation of new behaviours and generally agree that intention-formation is the key to change (Connor \& Norman, 1996). While there is some concern that behavioural intentions do not necessarily culminate in actual behaviour change, a recent meta-analysis has established that changing intentions does in fact engender behavioural change to some degree (Webb \& Sheeran, 2006); and particularly when they are stated in the form of specific goals and plans (Gollwitzer, 1999; Webb \& Sheeran, 2005). However, this meta-analysis also showed that initial intentions have little effect on long-term behaviours.

There is a growing call to recognise behavioural maintenance as a distinct process from behavioural initiation (De Wit, 2006; Rothman, 2004; Wing, 2004). It is not just a question of persevering once one has changed the behaviour. Maintenance includes alternating periods of success and failure and requires continual evaluation, adjusting one's goals and plans and solving new problems in the face of ever-changing circumstances. More research needs to be done to uncover which cognitive and affective factors play a role in this process. Social Cognitive Theory (Bandura, 1977; 1998) and more recent models, such as the Health Action Process Approach (Schwarzer, 2001), emphasize the pivotal role of self-efficacy in both the initiation and maintenance of behaviour; however, to our knowledge, no study has been able to establish the role of self-efficacy in predicting health behaviours over a longer time-span (Linde, Rothman, Baldwin, \& Jeffery, 2006).

Alternatively, the Relapse Prevention Approach (Marlatt, 1985) suggests that anticipation may be the key to realise sustained behavioural change. Relapse prevention techniques involve instructions aimed at teaching people to identify situations in which lapses in maintenances are likely to occur, to plan strategies in advance for avoiding lapses, and to get back on track should they occur (Jeffery et al., 2000). Relapse prevention has primarily focused on addictive behaviours, but the concept of anticipation could certainly apply to diabetes management, as a successful anticipation of barriers could help patients to avoid them.

In this context, we present proactive coping as a promising concept that has the potential to bridge the gap between behavioural change and behavioural maintenance. First introduced by Aspinwall and Taylor (1997), the proactive coping model describes the efforts people undertake in advance of a potentially stressful event to prevent or modify its form before it occurs. As such, proactive coping takes a selfregulatory perspective in explaining how people continue to strive for long-term goals in spite of many potential threats. Moreover, it emphasizes that people do not only react to real and specific threats and stressors in the here and now (reactive coping) or near future (anticipatory coping) but also may anticipate a wide array of potential future threats and act accordingly (proactive coping). As such, proactive coping occurs temporally prior to reactive and anticipatory coping, as people can also act early on before threats 
Thoolen, B.J., Ridder, D. de, Bensing, J., Gorter, K., Rutten, G. Beyond good intentions: the role of proactive coping in achieving sustained behavioural change in the context of diabetes management. Psychology \& Health: 2009, 24(3), 237-254

become an issue. Translated to diabetes, patients are proactive when they engage in self-management to prevent potential symptoms and long-term complications from occurring. And, more concretely, these patients act proactively when they do not just start on a rigorous diet or exercise plan, but first consider in advance the many potential barriers and situations which may undermine these behaviours and take preventive action when necessary.

According to Aspinwall and Taylor, proactive coping is a natural process which most of us apply to some degree in our daily lives. It involves the timely accumulation of resources, the continual anticipation and appraisal of potential threats, the development and realisation of strategies to offset these threats, and the use of feedback to assess both the effectiveness of one's strategies and the viability of one's goals. The concept has been applied to a wide range of themes, including aging, personal development and coping with life stressor and chronic disease (e.g. Aspinwall, 2006; Bode, De Ridder, \& Bensing, 2006; Ouwehand, De Ridder, \& Bensing, 2006; Schreurs, Colland, Kuijer, De Ridder, \& Den Elderen, 2003). These studies have demonstrated that people who take a future-oriented and proactive approach to their lives are more successful in avoiding stressors and are more likely to achieve their long-term goals. Proactive coping suggests that patients with diabetes who think about their self-management goals prior to acting, anticipate potential threats to their goals, and plan and evaluate their progress accordingly, should be more successful in achieving and maintaining an optimal self-management.

\section{Objectives of the study}

In the present study, we wish to examine the effectiveness of a 12-week proactive intervention for patients recently diagnosed with type-2 diabetes The main aim of this intervention was to teach these patients to become more proactive and self-reliant in their diabetes management (Thoolen, De Ridder, Bensing, Gorter, \& Rutten, 2008). We hypothesised that a proactive intervention will help patients to initiate selfcare behaviours and teach them the necessary skills to anticipate and deal with potential barriers to goalmaintenance, increasing their proactive skills, intentions, self-efficacy and, ultimately, help them maintain their self-care over time. Two major questions will be dealt with. First, we will investigate whether patients who received the intervention show better outcomes (intentions, self-efficacy, proactive coping, self-care behaviours and weight) than control patients, immediately after the intervention and nine months later. Second, we will examine whether proactive coping, as achieved at the end of the course, predicts long-term self-management, when set against other leading predictors of self-care behaviours, such as self-efficacy, intentions and previous behaviours. We hypothesise that proactive coping may be more successful than intentions and self-efficacy in predicting self-care maintenance because it empowers patients to appreciate and deal with a wide range of barriers and situations they may encounter.

\section{METHODS}

\section{Procedure}

A prospective randomised design was employed to examine the effectiveness of the intervention Beyond Good Intentions in patients recently diagnosed with type-2 diabetes during a screening trial. Following consent, patients were randomly assigned to one of two treatment groups, which were not blinded for either the patients or investigators. The control group received a brochure on diabetes self-management. The intervention group was offered a self-management course which lasted 12 weeks. Both groups were followed for 12 months, receiving questionnaires at baseline (T0, 0 months), immediately after the course (T1, 3 months) and at 12 months (T2).

\section{Proactive intervention}

Led by a registered nurse, the intervention consists of two individual and four group sessions, spread out over 12 weeks. In these sessions, patients discuss their experiences with diabetes (individual session), work on personally relevant goals in the domains of physical exercise, diet and medication (group sessions), and complete the course with a final individual session to evaluate their progress and plans for the future.

The group sessions last $2 \mathrm{~h}$ and all have the same basic structure. After a brief introduction on a specific self-care theme, patients are invited to share their beliefs, emotions and experiences. Subsequently, they are stimulated to formulate a personally relevant goal and work on this according to the proactive 5-step plan. This 5-step plan forms the core of the course, helping patients to set small, concrete and attainable goals (step 1), recognise conditions for and barriers to goal achievement (step 2), generate strategies for solving potential problems in specific situations (step 3), formulate necessary actions in the form of concrete and 
Thoolen, B.J., Ridder, D. de, Bensing, J., Gorter, K., Rutten, G. Beyond good intentions: the role of proactive coping in achieving sustained behavioural change in the context of diabetes management. Psychology \& Health: 2009, 24(3), 237-254

specific action plans (step 4), and consider beforehand how they are going to evaluate their progress (step 5). Finally, participants are asked to act on their plan, to rehearse the desired behaviour, and to keep a written daily register of goal-attainment over 2 weeks, giving them time to practice and evaluate.

During the sessions, the nurse primarily functions as coach, facilitating group interaction and practice with the proactive skills. Mental simulation is employed in each session to help patients become more proactive, helping them anticipate potential barriers and virtually try out their goals and action plans (Taylor, Pham, Rivkin, \& Armor, 1998). Course material includes a patient workbook and a nurse's handbook (Thoolen, De Ridder, \& Bensing, 2004a,b).

In the present study, the course was given by three different nurses specifically trained. The course was run 13 times with an average of six patients per course.

\section{Participants}

Participants were recruited from the Dutch arm of the Addition study, an international multi-centre randomised controlled screening trial which investigates the effectiveness of a target-driven approach to reduce cardiovascular risk in patients with screen-detected type-2 diabetes from general practices in the southwest Netherlands (Lauritzen, Griffin, Borch-Johnsen, Wareham, \& Wolffenbuttel, 2000). Participants (aged 50-70) had been detected 3-33 months previously and were receiving either intensive multi-factorial treatment (lifestyle advice and protocol-driven tight control of blood glucose, cholesterol and blood pressure, including prescription of aspirin and ACE-inhibitors) or conventional treatment according to national guidelines since diagnosis.

After receiving approval from the Medical Ethics Committee of the University Medical Center, Utrecht, we approached 468 patients included in Addition and not suffering from serious physical or mental comorbidities (Figure 1). Of these, 227 (49\%) patients agreed to participate. Reasons for not participating included practical issues (36\%), lack of interest in research (36\%), satisfaction with one's (self) care (12\%) and lack of concern about diabetes (13\%). Participants were more educated than non-participants, but there were no other significant differences with regard to their sociodemographic characteristics or perceptions of diabetes (Thoolen, de Ridder, Bensing, Gorter, \& Rutten, 2007).

\section{[FIGURE 1]}

The 227 participants were randomly allocated to the intervention condition $(n=119)$ or control condition $(n=108)$. Randomisation occurred within each general practice, based on a computer generated assignment. Patients in the intervention condition were assigned to specific courses depending on their medical treatment (intensive $v s$. usual-care) and their place of residence. However, the study took place in a relatively rural and extensive region and it was not always possible to assign patients to a course nearby. For 30 patients, distance from the course, lack of transportation and other obligations made it impossible to participate in any of the courses. In collaboration with these patients, it was therefore decided to exclude them from the rest of the study.

As such, 197 patients were able to take part in the study. Of the 89 participants in the intervention condition, 11 dropped out during the study. Reasons for dropout were all due to personal circumstances (e.g. time, illness and limited mobility). Of the 108 participants in the control group, six patients dropped out; two patients had difficulty filling out the forms, three patients suffered from ill health, and one patient died. A total of 180 patients participated in the study and completed all three questionnaires, with 78 completing the intervention and 102 in the control condition. The characteristics of these participants are shown in Table 1. There were no significant differences between the intervention and control groups on any variable, suggesting that the randomisation process was successful.2

\section{[TABLE 1]}

Furthermore, patients who were not able to participate or dropped-out prematurely were less educated but did not differ significantly from participants on any other patient characteristic (Thoolen et al., 2007).

\section{Measures}

Questionnaires included sociodemographic information (age, gender and education level), proximal outcomes (intentions, self-efficacy and proactive coping measures) and self-care behaviours, measured at T0, T1 and T2. In addition, to verify these self-reported outcomes, we included a measure of weight change, collected from the patient's general practice at the beginning (T0) and end of the study (T2). 
Thoolen, B.J., Ridder, D. de, Bensing, J., Gorter, K., Rutten, G. Beyond good intentions: the role of proactive coping in achieving sustained behavioural change in the context of diabetes management. Psychology \& Health: 2009, 24(3), 237-254

\section{Intentions}

Intentions were measured using six items assessing patients' intentions, desires and expectations to respectively follow a diet, exercise regularly and take medication in the next week (Fishbein \& Ajzen, 1975). Scores were measured on a 5-point scale and summed to one total score with higher scores reflecting higher intentions. Reliability for the dietary, exercise and medication scales were 0.94, 0.97 and 0.90 respectively.

\section{Self-efficacy}

Self-efficacy was assessed using a revised questionnaire adapted from Lorig et al. (1996) and validated in a previous study (Kuijer \& De Ridder, 2003). The instrument assessed self-efficacy in performing specific behaviours to control the disease. The scale included 12 items, each of which began with 'How confident are you that you can ... .' with answers ranging from 'not at all confident' (1) to 'totally confident' (7). The scale resulted in a total score for general self-efficacy (Cronbach's $\alpha=0.84$ ) and domain specific scores for diet $(\alpha=0.70)$, exercise $(\alpha=0.77)$ and medication $(\alpha=0.79)$.

\section{Proactive coping}

Proactive coping was assessed using two measures. The Proactive Competence Inventory assesses the various competencies involved in proactive coping, including being able to recognise first signals of undesired changes, to recognise one's possibilities and opportunities, to translate wishes into plans, to think about alternative solutions, to ask for social support, to learn from setback and to reward oneself. Participants were asked to rate these skills in the context of their diabetes self-management in 12 items, with answers ranging from ' $1=$ not at all able' to ' 4 = very able'. The scale has been validated and applied in previous studies (Bode et al., 2006) and has been found to be reliable in differentiating between patients high and low in proactive competencies $(\alpha=0.89)$.

The second measure, the Proactive Diabetes Management Inventory, was specifically designed for this study to evaluate patients' success in implementing the proactive 5-step plan in the context of their selfmanagement. Patients were first asked if they had worked on a diabetes related health goal in the preceding month, and were subsequently asked to rate their goal attainment on a 10-point scale from $1=$ 'not at all', to $10=$ 'completely achieved my goal'. Patients were then asked how far they had used proactive concepts to achieve this goal. The instrument included 17 statements covering different aspects of the 5-step plan, with answers ranging from $1=$ 'definitely not' to $5=$ 'definitely'. Items assessed whether patients thought about their goals beforehand, whether they anticipated and planned the strategies needed to achieve their goal, and whether they monitored their progress and adapted strategies accordingly. The scale resulted in a mean score ranging from 1 to 5 (Cronbach's $\alpha=0.86$ ).

\section{Self-care behaviours}

The assessment of patients' self-care included seven different instruments covering general and domain specific measures of self-management (diet, exercise and medication). General self-management behaviour was assessed using the revised summary of Diabetes Self-Care Activities measure (DSCA: Toobert, Hampson, \& Glasgow, 2000). The scale includes 10 items covering diet, exercise, blood-glucose testing and foot-care. For each domain, patients were asked 'Over the last 7 days, how often did you ...' summarised in a mean score of 0-7. The reliability of this scale is understandably low (Cronbach's $\alpha=0.63$ ) as it measures a wide range of behaviours. Nevertheless, because of its brief and lucid format, the scale is considered a valid and reliable alternative to more complex measurements and is commonly used in diabetes research. The subscales for diet $(\alpha=0.60)$, exercise $(\alpha=0.63)$ and medication (single item) were also calculated to verify the findings of the more specific instruments described below.

The Physical Activity Scale for the Elderly (PASE) was used as a more precise measurement of physical exercise (Schuit, Schouten,Westerterp, \& Saris, 1997). The PASE was developed to assess physical activity in the elderly looking beyond exercise to include occupational, household and leisure activities. The scale includes 15 items and translates the time spent on each activity into a composite score of 0-800, which reflects the amount of energy expended by the elderly person. The scale has been (cross-) validated with biomedical measures and has been found to be a brief and reliable alternative for measuring physical activity.

Diet was measured using the Kristal food habits questionnaire (Kristal, Shattuck, \& Henry, 1990) and the Dutch Fat Consumption Questionnaire (FCQ; Assema, Brug, Kok, \& Brants, 1992) to measure patients' restriction of (unhealthy-) fats. The Kristal food habits questionnaire (FHQ) recognises five different domains in how patients approach their diet when trying to reduce fats, assessing how often they engage in 
Thoolen, B.J., Ridder, D. de, Bensing, J., Gorter, K., Rutten, G. Beyond good intentions: the role of proactive coping in achieving sustained behavioural change in the context of diabetes management. Psychology \& Health: 2009, 24(3), 237-254

specific activities including modifying meat preparation, avoiding fat as a seasoning, replacing high-fat foods, substituting special low-fat for high-fat foods, and eating more fruits and vegetables. The scale includes 20 items with scores ranging from $1=$ 'never' to $4=$ 'always' (Cronbach's $\alpha=0.92$ ). Dietary fat intake was assessed with the FCQ, which is a valid and reliable instrument to rank individuals according to their dietary fat intake ( $\alpha=0.71)$. A higher score reflects a higher level of fat intake.

Medication adherence was assessed with the Medication Adherence Report Scale, a brief 5-item instrument which assesses the degree to which patients forget their medication, stop taking their medication or change dosages, with scores ranging from 1 = 'always true' to 5 = 'never true' (Horne \& Weinman, 1999). A higher mean score indicates higher adherence.

Finally, we also collected patients' weight and height as measured in their general practice. These were translated into a body mass index $(\mathrm{BMI}=$ weight $) /($ length $*$ length $)$.

\section{ANALYSES}

The effectiveness of the course was analysed using a repeated measures analyses of variance (ANOVA) to evaluate changes in performance over time on the primary measures. These included intentions, selfefficacy and proactive coping, the seven measures of self-management, and weight (BMI).

We first did a per protocol analysis on the 180 patients who stayed in their condition and completed all three questionnaires, comparing their performance over time. The group in which patients participated (Intervention vs. control) served as between subject variable and time (T0, T1, and T2) served as a within subject variable. Effect sizes are reported as partial eta squared (effect sizes: $0.01=$ small, $0.06=$ moderate and 0.14-large). In the presence of significant time by group interactions, additional post hoc analyses were done within the intervention group, comparing mean scores between $\mathrm{T} 0, \mathrm{~T} 1$ and $\mathrm{T} 2$ to examine whether changes achieved between T0 and T1 were maintained at T2. Analyses of weight change were based on changes in BMI between $\mathrm{T} 0$ and $\mathrm{T} 2$.

Recognising the potential influence of patients' treatment intensity (intensive $v s$. usual-care) and their time since diagnosis (greater or less than 1.5 years), but limited by the study's power, we controlled for these factors in separate analyses, dividing patients into four subgroups based on their screening date and allocation to a specific treatment within the Addition study. A repeated measures analysis was again applied, using both factors (intervention vs. control and groups based on treatment and disease duration) as between-subject variables and time as within subject variable.

Finally, to ensure that intervention effects were not overestimated (Hollis \& Campbell, 1999), we also included the 11 patients who dropped out during the treatment in an additional intention-to-treat like analysis. In case of missing values, we carried the T0 measure forward, thereby assuming that all missing responses remained constant. Repeated measures analyses were again employed to compare changes in time between the intervention group $(n=89)$ and the control group $(n=102)$ between T0 and T2.

To further analyse the specific effect of proactive coping (second question) we used hierarchical regression analyses. In this analysis, we wished to examine whether proactive coping was related to maintenance and, notably, whether the level of proactive competencies achieved at the end of the course (T1) could predict long-term self-management, achieved after 12 months (T2) when set against other potential predictors including initial self-management as measured at baseline and intentions and selfefficacy, as measured at T1. We first examined associations between the predictors and self-management within the intervention group. Subsequently, to test our hypothesis, we conducted separate hierarchical regression analyses within the intervention group that predicted each of the following self-management domains: general self-management (as measured by the DSCA), exercise (as measured by the PASE) and diet as measured by the FHQ (food habits) and FCQ (fat consumption).

In the first step, we included participants' baseline levels of self-management. In the second step, we included patient characteristics (gender, education and BMI) into the regression equation. In the third step, we included participants' intentions to diet and/or exercise, depending on the self-management domain under study. In the fourth step, we included domain specific measures of self-efficacy (general, diet or exercise). In the fifth and final step, we included proactive competencies. In each step, the effect of adding a predictor was tested for significance and Betas and changes in $R^{2}$ were examined. 
Thoolen, B.J., Ridder, D. de, Bensing, J., Gorter, K., Rutten, G. Beyond good intentions: the role of proactive coping in achieving sustained behavioural change in the context of diabetes management. Psychology \& Health: 2009, 24(3), 237-254

\section{RESULTS}

\section{Effectiveness of the intervention on intentions, self-efficacy and proactive coping}

Means, standard deviations and ranges for all measures of intentions, self-efficacy and proactive coping competence and behaviour are presented in Table 2, along with the results of the per protocol repeated measures analyses. Overall, there were no significant differences between groups at baseline, but patients who completed the course performed significantly better on nearly all measures at T1 and T2, reflected in the significant group xtime differences. Effect sizes indicated that changes were in the small to moderate range $\left(\eta p^{2}=0.02-0.10\right)$ Furthermore, post hoc analyses revealed that within the intervention group, there were no differences between scores at T1 and T2, indicating that improvements made at T1 were maintained at T2 (data not shown).

\section{[TABLE 2]}

The results also reveal a number of other important aspects. First, participants' mean scores on intentions were already quite high at baseline (overall mean of 4.4 on a scale from 1 to 5), particularly with regard to medication. Regardless, patients in the intervention group reported higher intentions to diet and exercise at T1 and maintained these at T2. Similarly, participants in both groups generally reported high self-efficacy (mean $=5.6$ on a scale from 1 to 7 ) at T0, while patients in the intervention group reported increases at T1 which remained stable at $\mathrm{T} 2$. As with intentions, group $\times$ time interaction were found for dietary selfefficacy $\left(\mathrm{F}(3.177)=5.3, p<0.01, \eta p^{2}=0.05\right)$ and exercise self-efficacy $\left(\mathrm{F}(3.177)=5.7, p<0.01, \eta p^{2}=\right.$ $0.06)$, but not for medication $(\mathrm{F}(3,115)=2.5, p=0.09)$, which was already extremely high at baseline (mean 6.8 (range 1-7)).

Patients in the intervention arm also showed significant and moderate improvements in their proactive competence $\left(\eta p^{2}=0.06\right)$, proactive behaviour $\left(\eta p^{2}=0.06\right)$ and goal attainment $\left(\eta p^{2}=0.06\right)$ and marginal changes in their proactive orientation $\left(\eta p^{2}=0.02\right)$. With regard to proactive behaviour, we could only compare those patients who had filled out the questionnaire at all three time-points. At T0, $80 \%$ of course participants had worked on a concrete goal, which increased to $100 \%$ at T1 and T2. Among controls, this figure remained stable at $80 \%$ from T0 to T2. As such, the intervention group not only report significantly higher proactive behaviour and goal attainment but significantly more of these patients mentioned goals at $\mathrm{T} 1$ and $\mathrm{T} 2$.

Finally, the inclusion of dropouts in the intention-to-treat like analysis did not lead to substantially different results.

\section{Effectiveness of the intervention on self-care and BMI}

Means, standard deviations and ranges for all self-care measures and weight (BMI) are presented in Table 3, along with the results of the per protocol repeated measures analyses, comparing changes in the intervention and control groups between T0, T1 and T2.

\section{[TABLE 3]}

Patients in the intervention group reported significant and positive changes in all self-care measures except for medication, which was already very high at baseline. While effect sizes in diet and exercise ranged from small to medium-large ( $\left.\eta p^{2}=3-13\right)$, changes could be considered clinically relevant. For example, mean changes in exercise measures reflected an average of at least one additional day of exercise per week.

Analyses of weight change verified the outcomes of the various self-management measures. There was a significant difference between groups with patients in the intervention arm dropping 0.6 in their BMI (or $1.9 \mathrm{~kg}$ ) while patients in the control group increased by $0.5(+1.3 \mathrm{~kg})$.

Controlling for patients' treatment intensity (intensive $v s$. usual-care) and their time since diagnosis (greater or less than 1.5 years) did not alter the significance of the results and generally only increased the effects of the intervention on the proximal measures of intentions, self-efficacy and proactive coping $\left(\eta p^{2}=\right.$ $0.04-0.11)$, self-care outcomes $\left(\eta p^{2}=0.04-0.11\right)$ and weight $\left(\eta p^{2}=0.16\right)$.

The intention-to-treat analysis also did not lead to significantly different results. Effect sizes in diet, exercise and weight change ranged from small to large $\left(\eta p^{2}=4-14\right)$. Changes in medication were not significant. 
Thoolen, B.J., Ridder, D. de, Bensing, J., Gorter, K., Rutten, G. Beyond good intentions: the role of proactive coping in achieving sustained behavioural change in the context of diabetes management. Psychology \& Health: 2009, 24(3), 237-254

\section{Proactive coping as a predictor for long-term self-management behaviour}

In a final series of analyses, we examined whether the level of proactive competence which course participants achieved during the course could predict long-term self-management on top of other predictors, including baseline self-management, sociodemographics, BMI, intentions and self-efficacy. Given that medication behaviour did not change during the intervention, we focused on dietary and exercise behaviour. Examination of the zero-order correlations revealed that self-management at T2 was strongly associated with most measures of baseline self-management (ranging from $r=0.43$ for the DSCA to 0.74 for the FCQ) and moderately associated with self-efficacy $(r=0.15-0.41)$ and proactive coping skills $(r=0.18-0.45)$. Self-management at $\mathrm{T} 2$ showed only small and generally non-significant associations with gender, education and BMI $(r=0.03-0.24)$ and intentions at T1 $(r=0.02-0.23)$. Finally, proactive competence was strongly associated with self-efficacy ( $r=0.41-0.56)$, but showed only small and non-significant associations with gender, education, BMI and intentions and non-significant to moderate associations with baseline self-management (from $r=-0.10$ in FCQ (T0) to $r=0.36$ for the FHQ).

Results of the hierarchical regression analysis are depicted in Table 4. Overall, proactive competence at $\mathrm{T} 1$ is a significant predictor of self-management, even when controlling for baseline self-management, intentions and self-efficacy. Patients with higher proactive competence reported significantly higher selfmanagement on the general self-management measure (the DSCA), the PASE (exercise) and the FHQ. In each case, adding proactive competence to the equation increased the explained variance significantly from between 3.3 and $6.6 \%$. While self-management at baseline remains the most important predictor of selfmanagement 12 months later, the level of proactive competencies which course participants attain is also a factor in how well they perform on self-management measures at the end of the study. It is also interesting to note that while self-efficacy was significantly associated with long-term self-management, it no longer predicted long-term self-management when proactive coping was added to the equation. Furthermore, intentions at T1 did not predict any of the self-management outcomes. Finally, neither gender nor education level predicted long-term self-management, while BMI was a significant predictor of exercise; patients who were heavier at the beginning of the study ultimately reported higher exercise levels at T2.

\section{[TABLE 4]}

\section{CONCLUSION AND DISCUSSION}

This study demonstrates that an intervention based on proactive coping is effective in getting newly diagnosed patients with type-2 diabetes to change their self-care behaviours and maintain these improvements over a longer time-span. Patients were able to grasp the concept of proactive coping and implemented these newly acquired skills in the context of self-management. Furthermore, patients in the intervention arm did not just become more proactive, they also increased their intentions to engage in their self-care, set more goals, reported a higher goal attainment and were significantly more confident in their ability to achieve optimal self-management. The success of the course is ultimately reflected in the sustained improvements in general self-care behaviours, domain specific measures of diet and exercise, and weight change, which course participants maintained up to nine months after the end of the course.

Further analysis reveals that the concept of proactive coping was an effective element within the course as a higher level of proactive coping competencies at the end of the course proved to be a significant predictor of long-term self-care behaviour in three out of four measures, even when controlling for baseline self-care, intentions and self-efficacy. In fact, intentions and self-efficacy proved to be poor predictors of self-care maintenance, particularly when proactive coping was added to the equation.

With regard to intentions, it is important to note that most newly diagnosed patients could already be considered strong intenders at the start of our study. At baseline, patients scored high on all intention measures and $80 \%$ of all patients, regardless of their allocation, could name a specific self-management goal on which they had been working. Therefore, given that most patients who take part in such interventions are already intending to change, interventions should perhaps focus less on motivational factors, and instead focus on helping participants to achieve their good intentions.

With regard to self-efficacy, we did find that it was associated with self-care; however, self-efficacy was not a good predictor of long-term self-care behaviour. This finding agrees with other recent studies which also found that self-efficacy may be a particularly important motivator when initiating new patterns of behaviour, but it may not help patients to maintain these changes over an extended time frame (e.g. Linde et 
Thoolen, B.J., Ridder, D. de, Bensing, J., Gorter, K., Rutten, G. Beyond good intentions: the role of proactive coping in achieving sustained behavioural change in the context of diabetes management. Psychology \& Health: 2009, 24(3), 237-254

al., 2006). This could reflect a shift in decision criteria; once people have initiated a new behaviour, the decision to continue is more whether they are satisfied with the outcomes and want to stick with it rather then whether they can (Rothman, 2004).

So why does proactive coping appear to be more effective in self-care maintenance? We suggest that while increased intentions and self-efficacy may stimulate patients to improve their self-care behaviour, it does not necessarily prepare them for many barriers and goal-conflicts that they may encounter when trying to maintain their new behaviours. Interventions based on social cognitive theories address patients' skills and barriers, but they generally focus on their problems and motivation in the here and now, and do not consider shifts in patients' lives which threaten their self-management goals and competencies. Proactive coping, with its focus on anticipation, planning and continued evaluation of self-management activities, may help patients to become more aware of threats to their self-care behaviours and act accordingly before such threats can undermine their behaviours. There may be four reasons for this. First, thinking about their goals in advance helps patients to become aware of other competing goals, habits and activities which may undermine their motivation to maintain their self-care. Second, thinking about goals also helps patients to recognise their limited resources, thereby helping them to set concrete goals which are achievable. Third, by recognising a whole array of potential threats, patients can plan their activities and generate alternative strategies to deal with problem situations as they arise. Finally, proactive coping also stresses the importance of evaluation, learning to assess one's goals, monitoring the environment for potential stressors, and evaluating the success of one's activities to deal with these threats.

The effectiveness of the proactive intervention over a wide range of outcomes is convincing, but it is also appropriate to consider the specific effects on different domains of self-management. With regard to diet and exercise, effect sizes were in the small to moderate-strong range. The fact that we did not find strong effects may reflect our focus on small, achievable goals. We informed patients of the self-management guidelines, but stimulated them to choose realistic goals tailored to their personal circumstances. Thus, for patients who never exercised, a goal of exercising four to five times a week (guideline) would probably be unrealistic and patients would therefore usually begin with a goal of two to three times a week. While this approach appears to have helped patients to maintain their goals, it could potentially diminish the effects of the intervention and may also explain the differences between instruments, as one instrument is more sensitive to small changes in behaviour than others. Nevertheless, we followed evidence from other studies which also suggest that the focus on small, concrete and achievable goals will ultimately lead to more sustained behavioural change (e.g. Schreurs et al., 2003). Similarly, although our focus on specific domains such as exercise and dieting did steer the goals of the patients to some degree, patients were free to work on any self-management goal which they deemed important. In this sense, the instruments used to measure changes in self-care behaviours may not be sensitive to the wide range of goals which patients had, which included social support seeking, stress-management, dealing with erectile dysfunction, etc. From this perspective, the fact that all intervention patients set goals and were better at achieving their goals may be a better indicator of the effectiveness of the intervention. Finally, the fact that patients maintained the improvements in their self-care beyond the program is heartening, but they did not report further improvements, suggesting that they may need additional support in the form of a booster session to help and stimulate them to set new goals.

Looking at medication use, patients all reported very high medication adherence at the beginning of the study, thus leaving very little room for change. Other studies also generally find that patients with diabetes have the least difficulty with their medication (Glasgow et al., 1998), but the outcomes of the present study seem overly optimistic and do raise concerns about the potential for social desirability. However, the measure of medication adherence used here was specifically designed to overcome this problem (Horne \& Weinman, 1999). It could thus very well be that patients in this study were, in fact, very adherent to their medication regimen.

This brings us to the limitations of the present study. Our emphasis on self-reported measures of self-care could be considered a first limitation. However, we attempted to control for this by using multiple measures for each self-care domain. Furthermore, the randomisation process itself also controlled for this aspect. Finally, we also examined patients' weight change and found that the intervention group lost a significant amount of weight, which in itself gives some hard evidence for the effectiveness of the intervention.

Another possible limitation of this study was its position within an ongoing medical trial, and in particular the differentiation of patients by treatment intensity and disease duration; however, in additional analyses we found that patients profited equally from the intervention regardless of their treatment or time since 
Thoolen, B.J., Ridder, D. de, Bensing, J., Gorter, K., Rutten, G. Beyond good intentions: the role of proactive coping in achieving sustained behavioural change in the context of diabetes management. Psychology \& Health: 2009, 24(3), 237-254

diagnosis. Another issue in this study is the relatively low response rate combined with the dropout in the intervention arm of our study which could suggest that we treated a selected group of patients. However, an additional non-response study revealed that education was the only factor differentiating participants from non-participants and dropouts; participants did not differ from these groups with regard to their illness perceptions (e.g. perceived seriousness, vulnerability and self-efficacy), self-management behaviour or other patient characteristics. Furthermore, in a preliminary study we found that education level was not associated with patients' evaluations or short-term outcomes, suggesting that our study can be generalised, at the least to patients diagnosed via a screening trial (Thoolen et al., 2007). In practice, reaching these less educated patients may be less difficult. If the course could be given in patients' local communities and at different times, it could also reach less educated and/or poorer patients who have less flexibility with regard to transportation and work hours.

The position of this study within the ADDITION study is also a strength as it allows for additional followup of patients' weight up to 5 years. The weight loss at nine month follow-up is heartening; but recent studies suggest that a longer follow-up is necessary to examine if patients truly are able to maintain their weight loss (Mann et al., 2007). For this reason, patients in the control group will not be receiving the intervention in the near future.

In sum, an intervention based on proactive coping appears promising in the context of diabetes management. The study also has several other implications. The present study adds fuel to the debate on the role of intentions and self-efficacy in achieving sustained behaviour change, and we would suggest that other theories and interventions are needed to explain, predict and influence goal maintenance. This study is one step further in suggesting that future orientation (and anticipatory strategies) may be one of the effective ingredients which determines health behaviour maintenance. From this perspective, the intervention has been tested and appears promising for a host of other chronic diseases which require self management (Schreurs et al., 2003). Finally, for the present, the intervention Beyond Good Intentions offers a brief and effective alternative self-management intervention for patients recently diagnosed with type-2 diabetes, as it helps patients to look beyond their good intentions and realise their goals in a practical 5-step plan which is easily applied in the clinical setting.

\section{NOTES}

1. See Thoolen et al., in press for a detailed description of the theoretical development of the course.

2. While there were no differences between intervention and control group, we did find that screendetected patients differed from each other in terms of anxiety, self-efficacy and perceived vulnerability, based on their medical treatment and disease duration (Thoolen et al., 2006), notably, intensively treated patients show more distress and less self-efficacy in the first year while usual care patients report relatively more distress and less self-efficacy two to three years after diagnosis. There were no significant differences with regard to self-care.

\section{REFERENCES}

1. Adriaanse, MC , Snoek, FJ , Dekker, JM , van der Ploeg, HM and Heine, RJ (2002) Screening for type-2 diabetes: An exploration of subjects' perceptions regarding diagnosis and procedure. Diabetes Medicine 19 , pp. 406-411.

2. Aspinwall, LG (2005) The Psychology of future-oriented thinking: From achievement to proactive coping, adaptation and aging. Motivation and Emotion 29 , pp. 203-234.

3. Aspinwall, LG and Taylor, SE (1997) A stitch in time: Self-regulation and proactive coping. Psychological Bulletin 121 , pp. 417-436.

4. Assema, P. , Brug, J. , Kok, G. and Brants, H. (1992) The reliability and validity of a Dutch questionnaire on fat consumption as a means to rank subjects according to individual fat intake. European Journal of Cancer Prevention 1 , pp. 375-380.

5. Bandura, A. (1977) Self-efficacy: Toward a unifying theory of behavior change. Psychological Review 84 , pp. 191-215.

6. Bandura, A. (1998) Health promotion from the perspective of social cognitive theory. Psychology and Health 13 , pp. 623-649.

7. Bode, C. , De Ridder, DT and Bensing, JM (2006) Preparing for aging: Development, feasibility and preliminary results of an educational program for midlife and older based on proactive coping theory. Patient Education and Counseling 61 , pp. 272-278. 
Thoolen, B.J., Ridder, D. de, Bensing, J., Gorter, K., Rutten, G. Beyond good intentions: the role of proactive coping in achieving sustained behavioural change in the context of diabetes management. Psychology \& Health: 2009, 24(3), 237-254

8. Connor, M. and Norman, P. Connor, M. and Norman, P. (eds) (1996) The role of social cognitions in predicting health behaviors. Predicting health behavior pp. 1-22. Open University Press, Buckingham, UK

9. De Wit, J. de Ridder, DTD and de Wit, J. (eds) (2006) Maintenance of health behavior change: Additional challenges for self-regulation theory, research and practice. Self-regulation in health behavior pp. 193215. John Wiley \& sons, West Sussex, UK

10. Fishbein, M. and Ajzen, I. (1975) Belief, attitude, intention and behavior: An introduction to theory and research Addison-Wesley , London

11. Glasgow, RE and Eakin, EG Shumaker, SA, Schron, EB , Ockene, JK and McBee, WL (eds) (1998) Issues in diabetes self-management. The handbook of health behaviour change pp. 435-461. Springer , New York

12. Gollwitzer, PM (1999) Implementation intentions: Strong effects of simple plans. American Psychologist 54 , pp. 493-503.

13. Gonder-Frederick, LA and Cox, DJ (2002) Diabetes and behavioral medicine: The second decade. Journal of Consulting and Clinical-Psychology 70 , pp. 611-625.

14. Hollis, S. and Campbell, F. (1999) What is meant by intention to treat analysis? Survey of published randomised controlled trials. British Medical Journal 319 , pp. 670-674.

15. Horne, R. and Weinman, J. (1999) Patient's beliefs about prescribed medicines and their role in adherence to treatment in chronic physical illness. Journal of Psychosomatic Research 47 , pp. 555-567.

16. Jeffery, RW , Drewnowski, A. , Epstein, LH , Stunkard, AJ , Wilson, GT Wing, RR et al. (2000) Longterm maintenance of weight loss: current status. Health Psychology 19 , pp. 5-16.

17. Kristal, AR , Shattuck, AL and Henry, HJ (1990) Patterns of dietary behavior associated with selecting diets low in fat: Reliability and validity of a behavioral approach to dietary assessment. Journal of the American Dietetic Association 90 , pp. 214-220.

18. Kuijer, RG and De Ridder, DTD (2003) Discrepancy in illness related goals and quality of life in chronically ill patients: the role of self-efficacy. Psychology and Health 18 , pp. 313-330.

19. Lauritzen, T. , Griffin, S. , Borch-Johnsen, K. , Wareham, NJ and Wolffenbuttel, BHR (2000) The ADDITION study: Proposed trial of the cost-effectiveness of an intensive multifactorial intervention on morbidity and mortality among people with Type 2 diabetes detected by screening. International Journal of Obesity and Related Metabolic Disorders 24 , pp. S6-S11.

20. Linde, JA, Rothman, AJ, Baldwin, AS and Jeffrey, RW (2006) The impact of self-efficacy on behavior change and weight change among overweight participants in a weight loss trial. Health Psychology 25 , pp. 282-291.

21. Lorig, K. , Stewart, A. , Ritter, P. , Gonzales, V. , Laurent, D. and Lynch, J. (1996) Outcome measures for health education and other health care interventions Sage, Thousand Oaks, CA

22. Mann, TA, Tomiyama, J. , Westling, E. , Lew, A. , Samuels, B. and Chatman, J. (2007) Medicare's search for effective obesity treatments: Diets are not the answer. American Psychologist 62 , pp. $220-233$.

23. Marlatt, GA and Gordon, JR (1985) Relapse prevention Guilford, New York 24. Norris, SL , Engelgau, MM and Venkat Narayan, KM (2001) Effectiveness of self-management training in type 2 diabetes: A systematic review of randomized controlled trials. Diabetes Care 24 , pp. 561-587.

25. Ouwehand, C. , De Ridder, DT and Bensing, JM (2006) Situational aspects are more important in shaping proactive coping behavior than individual characteristics: A vignette study among adults preparing for aging. Psychology and Health 21 , pp. 809-825.

26. Rothman, A. (2000) Toward a theory based analysis of behavioral maintenance. Health Psychology 15 , pp. 64-69.

27. Rothman, A. Baumeister, RF and Vohs, KD (eds) (2004) Self-regulation and behavior change. Disentangling behavioral initiation and behavioral maintenance. Handbook of self-regulation. Research theory and applications pp. 130-148. Guilford, New York

28. Schreurs, KMG , Colland, VT, Kuijer, RG , De Ridder, DTD and Den Elderen, T (2003) Development, content and process evaluation of a short self-management intervention in patients with chronic diseases requiring self-care behaviours. Patient Education and Counseling 53, pp. 133-141.

29. Schuit, AJ , Schouten, EG , Westerterp, KR and Saris, WHM (1997) Validity of the Physical Activity Scale for the Elderly (PASE): According to Energy Expenditure assessed by the Doubly Labeled Water Method. Journal of Clinical Epidemiology 50 , pp. 541-546.

30. Schwarzer, R. (2001) Social cognitive factors in changing health related behavior. Current Directions in Psychological Science 10 , pp. 47-51.

31. Steed, L. , Cooke, D. and Newman, S. (2003) A systematic review of psychosocial outcomes following education, self-management and psychological interventions in diabetes mellitus. Patient Education and Counseling 51 , pp. 5-15.

32. Taylor, SE, Pham, LB , Rivkin, ID and Armor, DA (1998) Harnessing the imagination. Mental simulation, self-regulation, and coping. American Psychologist 53 , pp. 429-439. 
Thoolen, B.J., Ridder, D. de, Bensing, J., Gorter, K., Rutten, G. Beyond good intentions: the role of proactive coping in achieving sustained behavioural change in the context of diabetes management. Psychology \& Health: 2009, 24(3), 237-254

33. Thoolen, BJ , De Ridder, DTD and Bensing, JM (2004a) Geen Woorden Maar Daden. Werkboek

Universiteit Utrecht, Utrecht

34. Thoolen, BJ , De Ridder, DTD and Bensing, JM (2004b) Geen Woorden Maar Daden. Handleiding voor Verpleegkundigen Universiteit Utrecht , Utrecht

35. Thoolen, BJ , De Ridder, DTD , Bensing, JM , Gorter, KJ and Rutten, GE (2006) Psychological outcomes in screen-detected patients with type-2 diabetes. Diabetes Care 29 , pp. 2257-2262.

36. Thoolen, BJ , De Ridder, DTD , Bensing, JM , Gorter, KJ and Rutten, GE (2008) Beyond good intentions: The development and evaluation of a proactive self-management course for patients recently diagnosed with type-2 diabetes. Health Education Research 23 , pp. 53-61.

37. Thoolen, BJ , De Ridder, DTD , Bensing, JM , Gorter, KJ and Rutten, GE (2007) Who participates in diabetes self-management interventions? Issues of recruitment and retainment. The Diabetes Educator 33 , pp. 465-474.

38. Toobert, DJ , Hampson, SE and Glasgow, RE (2000) The summary of diabetes self-care activities measure: Results from 7 studies and a revised scale. Diabetes Care 23 , pp. 943-950.

39. Warsi, A. , Wang, PS and Lavalley, MP (2004) Self-management education programs in chronic disease: A systematic review and methodological critique of the literature. Archives of Internal Medicine 164 , pp. 1641-1649.

40. Webb, TL and Sheeran, P. (2005) Integrating concepts from goal theories to understand the achievement of personal goals. European Journal of Social Psychology 35 , pp. 69-96.

41. Webb, TL and Sheeran, P. (2006) Does changing behavioral intentions engender behavior change? A meta-analysis of the experimental evidence. Psychological Bulletin 132 , pp. 249-268.

42. Whittemore, R. (2000) Strategies to facilitate change associated with diabetes mellitus. Journal of Nursing Scholarship 3 , pp. 225-232.

43. Wing, RR (2000) Cross-cutting themes in maintenance of behavior change. Health Psychology 19 , pp. 3-4.

\section{FIGURES}

Figure 1. Recruitment and participation in the study beyond good intentions.

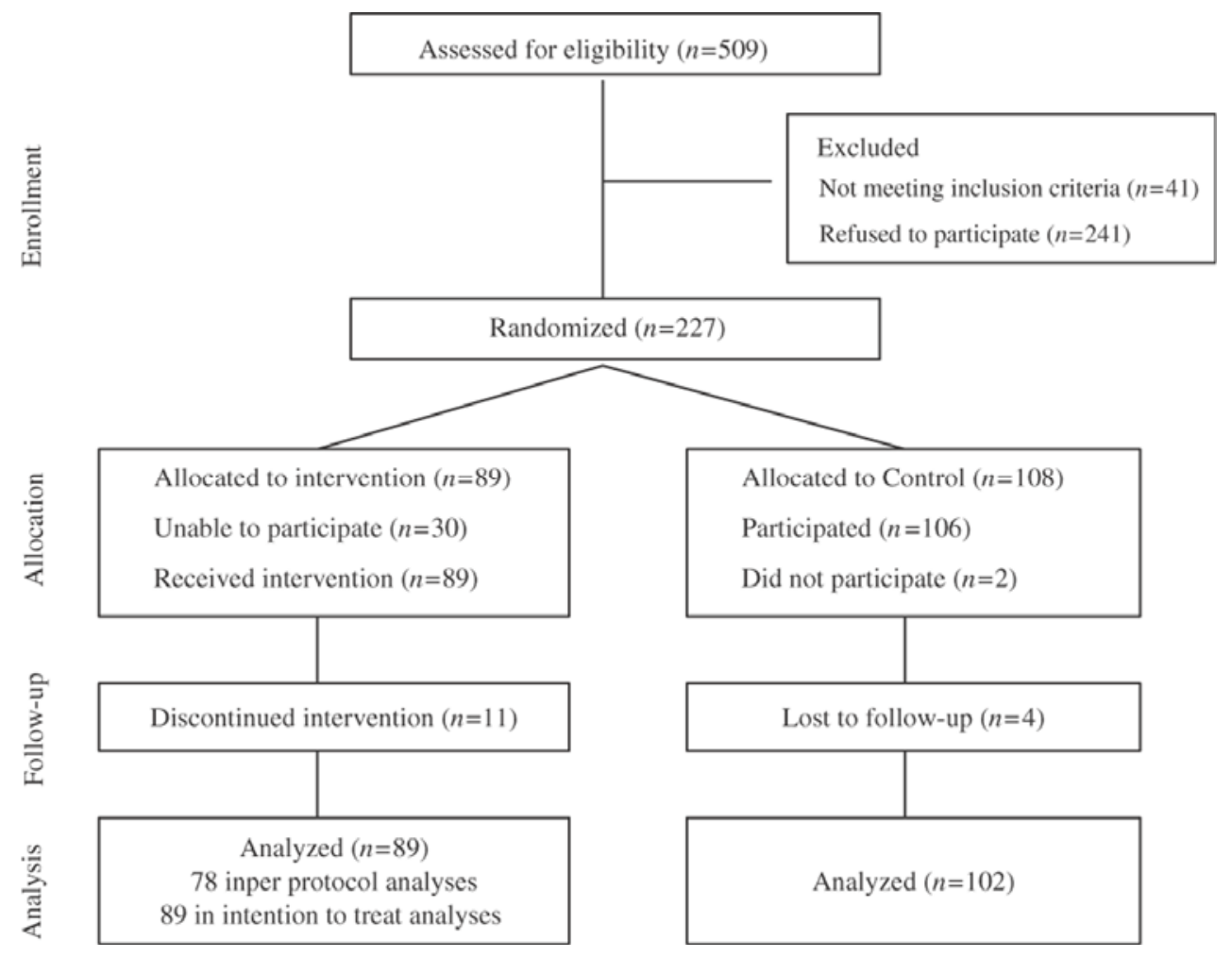


Thoolen, B.J., Ridder, D. de, Bensing, J., Gorter, K., Rutten, G. Beyond good intentions: the role of proactive coping in achieving sustained behavioural change in the context of diabetes management. Psychology \& Health: 2009, 24(3), 237-254

\section{TABLES}

Table 1. Demographic and medical characteristics.

\begin{tabular}{|c|c|c|c|}
\hline & $\begin{array}{l}\text { Intervention } \\
\quad(n=78)\end{array}$ & $\begin{array}{c}\text { Control } \\
(n=102)\end{array}$ & $p$-value ${ }^{a}$ \\
\hline \multicolumn{4}{|l|}{ Age } \\
\hline Mean (SD) & $62.0(4.9)$ & $61.9(5.6)$ & 0.96 \\
\hline \multicolumn{4}{|l|}{ Gender $\%$} \\
\hline Male & 64 & 55 & 0.24 \\
\hline Female & 36 & 45 & \\
\hline \multicolumn{4}{|l|}{ Education level ${ }^{\mathrm{A}}$} \\
\hline Mean (SD) & $3.4(1.6)$ & $3.1(1.5)$ & 0.15 \\
\hline \multicolumn{4}{|l|}{ Employed $\%$} \\
\hline Employed & 30 & 22 & 0.17 \\
\hline Unemployed & 70 & 78 & \\
\hline \multicolumn{4}{|l|}{ Treatment $\%$} \\
\hline Intensive & 41 & 45 & 0.44 \\
\hline Usual-care & 59 & 55 & \\
\hline Disease duration & $18.4(8.8)$ & $17.0(9.0)$ & 0.31 \\
\hline In months (SD) & & & \\
\hline
\end{tabular}

Notes: ${ }^{a} p$-value for ANOVA (age, education, disease duration) or $x^{2}$ (all other variables).

${ }^{b}$ Level of education was measured on a 6-point scale $(1=$ lowest, $6=$ highest level).

Table 2. The effectiveness of the intervention on intentions, self-efficacy and proactive coping: based on a repeated measures of analyses comparing changes in control $(n=102)$ and intervention groups $(n=78)$ at baseline (T0), 3 months (T1) and 12 months (T2).

\begin{tabular}{|c|c|c|c|c|c|c|}
\hline Scale & (range) & $\begin{array}{c}\text { T0 } \\
\text { Mean }(S D)\end{array}$ & $\begin{array}{c}\text { T1 } \\
\text { Mean }(S D)\end{array}$ & $\begin{array}{c}\mathrm{T} 2 \\
\text { Mean }(S D)\end{array}$ & $\begin{array}{l}\text { Group } \times \text { Time } \\
\text { interactions }\end{array}$ & $\begin{array}{c}\text { Effect size } \\
n p^{2}\end{array}$ \\
\hline Diet intention & $(1-5)$ & & & & & \\
\hline Intervention & & $4.4(0.7)^{\mathrm{a}, \mathrm{b}}$ & $4.6(0.6)^{\mathrm{a}}$ & $4.7(0.7)^{\mathrm{a}}$ & $F(3,177)=3.3^{*}$ & 0.02 \\
\hline Control & & $4.4(0.7)$ & $4.4(0.6)$ & $4.4(0.6)$ & & \\
\hline Exercise intention & $(1-5)$ & & & & & \\
\hline Intervention & & $3.9(1.1)^{\mathrm{a}, \mathrm{b}}$ & $4.5(0.8)^{2}$ & $4.5(1.0)^{\mathrm{b}}$ & $F(3,177)=10.4^{* * *}$ & 0.06 \\
\hline Control & & $4.0(1.0)$ & $4.1(0.9)$ & $4.1(1.0)$ & & \\
\hline Medication intention & $(1-5)$ & & & & & \\
\hline Intervention & & $4.9(0.3)$ & $4.9(0.2)$ & $4.9(0.2)$ & $F(3,113)=0.08$ & - \\
\hline Control & & $4.9(0.3)$ & $4.9(0.2)$ & $4.9(0.2)$ & & \\
\hline General self-efficacy & $(1-7)$ & & & & & \\
\hline Intervention & & $5.6(0.9)^{\mathrm{a}, \mathrm{b}}$ & $5.9(0.7)^{2}$ & $5.9(0.7)^{b}$ & $F(3,177)=8.3^{* * *}$ & 0.06 \\
\hline Control & & $5.6(0.9)$ & $5.6(0.9)$ & $5.6(0.9)$ & & \\
\hline Proactive competence & $(1-4)$ & & & & & \\
\hline Intervention & & $2.9(0.6)^{\mathrm{a}, \mathrm{b}}$ & $3.1(0.6)^{\mathrm{a}}$ & $3.2(0.6)^{\mathrm{b}}$ & $F(3,177)=8.7^{* *}$ & 0.06 \\
\hline Control & & $2.9(0.6)$ & $3.0(0.6)$ & $3.0(0.6)$ & & \\
\hline Proactive behavior & $(1-5)$ & & & & & \\
\hline Intervention & & $2.6(0.9)^{a, b}$ & $3.1(0.9)^{\mathrm{a}}$ & $3.0(0.9)^{\mathrm{b}}$ & $F(3,130)=6.9^{* *}$ & 0.06 \\
\hline Control & & $2.6(1.0)$ & $2.6(0.9)$ & $2.5(0.8)$ & & \\
\hline Goal attainment & $(1-10)$ & & & & & \\
\hline Intervention & & $5.4(2.4)^{a, b}$ & $6.7(2.2)^{\mathrm{a}}$ & $6.8(2.3)^{\mathrm{b}}$ & $F(3,130)=8.9 * *$ & 0.10 \\
\hline Control & & $6.1(2.1)$ & $6.0(2.1)$ & $5.9(2.1)$ & & \\
\hline
\end{tabular}

Notes: Means with different superscripts in a row differ significantly from each other at $p<0.05$ (Bonferonni test).

Group $\times$ time interactions reported in terms of within subject effects: $(*=p<0.05 ; * *=p<0.01$; $* * *=0.001)$.

Effect sizes are reported as partial Eta squared $\left(\eta p^{2}\right)$ for the within subject effects $(0.01=$ small, $0.06=$ moderate and $0.14=$ large). 
Thoolen, B.J., Ridder, D. de, Bensing, J., Gorter, K., Rutten, G. Beyond good intentions: the role of proactive coping in achieving sustained behavioural change in the context of diabetes management. Psychology \& Health: 2009, 24(3), 237-254

Table 3. The effectiveness of the intervention on self-care: based on a repeated measures of analyses comparing changes in control and intervention groups at baseline (T0), 3 months (T1) and 12 months (T2).

\begin{tabular}{|c|c|c|c|c|c|c|}
\hline & & $\begin{array}{c}\text { T0 } \\
\text { Mean } \\
(S D)\end{array}$ & $\begin{array}{c}\text { T1 } \\
\text { Mean } \\
(S D)\end{array}$ & $\begin{array}{c}\mathrm{T} 2 \\
\text { Mean } \\
(S D)\end{array}$ & $\begin{array}{l}\text { Group } \times \text { Time } \\
\text { interactions }\end{array}$ & $\begin{array}{c}\text { Effect size } \\
n p^{2}\end{array}$ \\
\hline General Self-care (DSCA) & $(0-7)$ & & & & & \\
\hline Intervention & & $3.5(1.0)^{\mathrm{a}, \mathrm{b}}$ & $4.3(08)^{\mathrm{ac}}$ & $4.1(0.9)^{\mathrm{bc}}$ & $F(3,177)=16.1$ & 0.08 \\
\hline Control & & $3.6(1.0)$ & $3.6(1.0)$ & $3.6(1.1)$ & & \\
\hline Exercise (subscale DSCA) & $(0-7)$ & & & & & \\
\hline Intervention & & $3.2(20)^{\mathrm{a}, \mathrm{b}}$ & $4.6(1.8)^{a}$ & $4.1(1.8)^{\mathrm{b}}$ & $F(3,177)=16.5 * * *$ & 0.09 \\
\hline Control & & $3.3(20)$ & $3.3(1.9)$ & $3.3(1.9)$ & & \\
\hline Exercise (PASE) & $(0-800)$ & & & & & \\
\hline Intervention & & $125(60)^{a, b}$ & $162(75)^{\mathrm{a}}$ & $152(76)^{b}$ & $F(3,177)=9.8^{* * *}$ & 0.06 \\
\hline Control & & $132(64)$ & $135(69)$ & $127(66)$ & & \\
\hline Diet (subscale DSCA) & $(0-7)$ & & & & & \\
\hline Intervention & & $5.0(1.2)^{\mathrm{a}, \mathrm{b}}$ & $5.6(1.0)^{\mathrm{a}}$ & $5.5(1.0)^{\mathrm{b}}$ & $F(3,177)=13.7^{* * *}$ & 0.07 \\
\hline Control & & $5.1(1.3)$ & $4.9(1.2)$ & $4.9(1.1)$ & & \\
\hline Dietary habits (FHQ) & $(1-4)$ & & & & & \\
\hline Intervention & & $2.5(0.4)^{\mathrm{a}, \mathrm{b}}$ & $2.8(0.4)^{\mathrm{a}}$ & $2.8(0.4)^{\mathrm{b}}$ & $F(3,177)=26.0^{* * *}$ & 0.13 \\
\hline Control & & $2.5(0.4)$ & $2.5(0.4)$ & $2.5(0.4)$ & & \\
\hline \multicolumn{7}{|l|}{ Fat consumption $(F C Q)$} \\
\hline Intervention & & $28.0(0.6)^{\mathrm{a}, \mathrm{b}} 2$ & $25.9(0.6)^{2} 2$ & $25.3(0.6)^{\mathrm{b}}$ & $F(3,177)=6.1^{* *}$ & 0.03 \\
\hline Control & & $27.1(0.6) \quad 2$ & $27.1(0.6) 2$ & $26.4(0.6)$ & & \\
\hline Medication (Mars) & $(1-5)$ & & & & & \\
\hline Intervention & & $4.8(0.5)$ & $4.9(0.2)$ & $4.9(0.2)$ & $F(3,113)=0.5$ & 0.00 \\
\hline Control & & $4.9(0.2)$ & $5.0(0.2)$ & $5.0(0.2)$ & & \\
\hline \multicolumn{7}{|c|}{ Medication subscale DSCA) (1-7) } \\
\hline Intervention & & $6.9(0.7)$ & $6.9(0.4)$ & $7.0(0.4)$ & $F(3,113)=0.01$ & 0.00 \\
\hline Control & & $6.9(0.7)$ & $6.9(0.4)$ & $6.9(0.3)$ & & \\
\hline \multicolumn{7}{|l|}{$B M I$} \\
\hline Intervention & & $30.3(5.2)$ & & $29.6(5.1)$ & $F(3,177)=32.4 * * *$ & 0.15 \\
\hline Control & & $29.7(5.1)$ & & $30.3(5.1)$ & & \\
\hline
\end{tabular}

Notes: Means with different superscripts in a row differ significantly from each other at $p<0.05$ (Bonferonni test).

Group $\times$ time interactions reported in terms of within subject effects: $(*=p<0.05 ; * *=p<0.01$; $* * * p<0.001)$.

Effect sizes are reported a spartial Eta squared $\left(\eta p^{2}\right)$ for the within subject effects $(0.01=$ small, $0.06=$ moderate and $0.14=$ large). 
Thoolen, B.J., Ridder, D. de, Bensing, J., Gorter, K., Rutten, G. Beyond good intentions: the role of proactive coping in achieving sustained behavioural change in the context of diabetes management. Psychology \& Health: 2009, 24(3), 237-254

Table 4. Hierarchical regression analysis for predictors of self-care 12 months after baseline, including intentions, self-efficacy and proactive coping as measured 3 months after baseline (T1).

\begin{tabular}{|c|c|c|c|c|c|c|c|c|}
\hline & \multicolumn{2}{|c|}{$\begin{array}{c}\text { General self-care } \\
\text { DSCA }\end{array}$} & \multicolumn{2}{|c|}{$\begin{array}{l}\text { Exercise } \\
\text { PASE }\end{array}$} & \multicolumn{2}{|c|}{$\begin{array}{l}\text { Diet habits } \\
\text { FHQ }\end{array}$} & \multicolumn{2}{|c|}{$\begin{array}{c}\text { Fat consumption } \\
\text { FCQ }\end{array}$} \\
\hline & Beta & $\Delta R^{2}$ & Beta & $\Delta R^{2}$ & Beta & $\Delta R^{2}$ & Beta & $\Delta R^{2}$ \\
\hline Step 1 & & $18.3^{* * *}$ & & $39.3^{* * *}$ & & $44.3 * * *$ & & $56.7^{* * *}$ \\
\hline Baseline self-care & $0.30 * *$ & & $0.60^{* * *}$ & & $0.52^{* * *}$ & & $0.70^{* * *}$ & \\
\hline $\begin{array}{l}\text { Step } 2 \\
\text { Gender } \\
\text { Education } \\
\text { BMI }\end{array}$ & $\begin{array}{r}-0.04 \\
-0.13 \\
0.12\end{array}$ & 2.8 & $\begin{array}{c}-0.02 \\
-0.05 \\
0.21\end{array}$ & 4.2 & $\begin{array}{r}-0.03 \\
0.12 \\
0.10\end{array}$ & 1.4 & $\begin{array}{r}0.02 \\
-0.10 \\
-0.10\end{array}$ & 1.9 \\
\hline $\begin{array}{l}\text { Step } 3 \\
\text { Diet Intention } \\
\text { Exercise Intention }\end{array}$ & $\begin{array}{r}-0.02 \\
0.09\end{array}$ & 1.9 & 0.07 & 0.6 & $\begin{array}{c}0.07 \\
-\end{array}$ & 1.5 & $\begin{array}{c}0.03 \\
-\end{array}$ & 0.1 \\
\hline $\begin{array}{l}\text { Step } 4 \\
\text { Self-efficacy }\end{array}$ & 0.13 & $6.0^{*}$ & -0.05 & 0.2 & 0.16 & $4.4^{*}$ & -0.15 & $2.3^{*}$ \\
\hline $\begin{array}{l}\text { Step } 5 \\
\text { Proactive competence }\end{array}$ & $0.30^{* *}$ & $6.6^{*}$ & $0.21^{*}$ & $3.3^{*}$ & $0.25^{* *}$ & $4.9^{* *}$ & -0.08 & 0.5 \\
\hline
\end{tabular}

Notes: Beta: based on outcomes of final model (step 5).

$\Delta R^{2}=$ indicates the change in predicted variance with each new step.

Significance: $*=p<0.05, * *=p<0.01, * *=p<0.001$.

gender nor education level predicted long-term self-management, while BMI was a significant predictor of exercise; patients who were heavier at the beginning of the study ultimately reported higher exercise levels at T2. 